\title{
Powder Characteristics of Fly Ash Beneficiated by Cold Plasma and Heat Treatment
}

\author{
Seung-Heun Lee ${ }^{\dagger}$, Un-Jin Cho, and Sung-Ku Kwon \\ Department of Materials Science and Engineering, Kunsan National Universtiy, Kunsan 54150, Korea
}

(Received October 6, 2015; Revised December 3, 2015; Accepted December 3, 2015)

\begin{abstract}
Cold plasma and heat treatment were selected as technologies to reduce unburned carbon in fly ash to less than $1.0 \%$. Both cold plasma and heat treatment made it possible to eliminate unburned carbon to less than $1.0 \%$. In the case of fly ash, which almost entirely eliminated unburned carbon with an ignition loss of $0.5 \%$, heat treatment caused adhesion among particles and the BET specific surface area rapidly decreased as the mean particle size increased. On the other hand, with cold plasma, unburned carbon elimination caused the BET specific surface area to decrease and, as no adhesion occurred among particles, the mean particle size became small. Also, cold plasma treatment allowed small spherical particles confined within the unburned carbon particles to be released with the elimination of the unburned carbon frame, so that the quantity of fine particles had a tendency to slightly increase.
\end{abstract}

Key words : Fly ash, Cold plasma, Heat treatment, Unburned carbon

\section{Introduction}

$\mathrm{F}$ ly ash is the fine powdered coal ash recovered from an electric dust collector by combustion in a temperature range around $1,500^{\circ} \mathrm{C}$ after injection of coal into a boiler after pulverization at a thermal power plant. ${ }^{1)}$ Domestically, although generation of the fly ash tends to be increased due to an increase in electric power consumption, utilization rates of fly ash are being gradually lowered due to environment changes and inadequacy of the key utilization technologies, requiring establishment of positive utilization measures. Domestic fly ash exhibits severe variation of about $2 \sim 10 \%$ in unburned carbon contents, making quality control quite difficult. Since lowering of liquidity and an increase in unity quantities occur particularly when the fly ash with high unburned carbon contents is used as an admixture, treatment facilities for reduction of unburned carbon are essential..$^{2-4)}$

Methods for elimination of unburned carbon include wind classification $^{5)}$, electrostatic classification ${ }^{6)}$, and flotation, ${ }^{7)}$ etc. Although wind classification or electrostatic classification is suitable for separation of large unburned carbon particles, elimination of even small unburned carbon particles is difficult. While flotation can remove even small unburned carbon particles, it has a disadvantage such as increased manufacturing costs due to the use of a foaming agent or addition of a drying process. ${ }^{7}$

\footnotetext{
${ }^{\dagger}$ Corresponding author : Seung-Heun Lee

E-mail : shlee@kunsan.ac.kr

Tel : +82-63-469-4733 Fax : +82-63-469-4731
}

The method which is currently in wide use by the industry is wind classification. In the wind classification, particle sizes are separated using a centrifugal force produced by wind force. ${ }^{5)}$ Since the wind classification can effectively classify down to $30-45 \mu \mathrm{m}$, sorting of unburned carbon particles is possible to a certain extent ${ }^{8)}$. However, it has characteristics of easy breakage as the unburned carbon has a low density accompanied by porosity in comparison with ash particles. Therefore, the wind classification has a limitation in reduction of unburned carbon, since the particles of unburned carbon are broken and moved to the part with a small particle diameter or collide with other particles to be further refined during rotation inside the classifier.

Recently, attempts have been made for utilization of fly ash an admixture for super flowing concrete as a new application. ${ }^{9)}$ However, when the fly ash containing unburned carbon is mixed with the super flowing concrete, there is a problem that control of liquidity is difficult. This is due to the fact that the unburned carbon in fly ash adsorbs a large amount of organic admixture which provides air volume and liquidity. ${ }^{10)}$ Therefore, if the unburned carbon can be eliminated to a level less than $1 \%$, the fly ash may be used as an admixture for super flowing concrete in a stable manner. While the heat treatment is available as a method capable of removing the unburned carbon in fly ash to less than $1 \%$, particle agglomeration phenomenon occurs by heating, resulting in a disadvantage such as lowering of powder characteristics.

In the present study, cold plasma method was incorporated to solve disadvantages of the heat treatment, and powder characteristics for the fly ash with unburned carbon removed by heat treatment and cold plasma method were 
reviewed. Although the cold plasma method has problems of large-capacity treatment, continuous process and economy, etc., the present study was performed with an objective of collecting basic data for commercialization in the future.

\section{Experimental Procedure}

\subsection{Fly ash}

For fly ash, what was discharged from a thermal power plant of pulverized coal combustion boiler has been employed. The loss on ignition was $6.0 \%$, Blaine specific surface area $380 \mathrm{~m}^{2} / \mathrm{kg}$, and the density $2.3 \mathrm{~g} / \mathrm{cm}^{3}$. As indicated in Table 1, the chemical composition of the employed fly ash showed a typical fly ash of pulverized coal. Physical properties of the fly ash are as shown in Table 2.

\subsection{Removal method for unburned carbon}

\subsubsection{Cold plasma method}

Plasmas are divided into two types. One of those is hightemperature plasma, and generally produced by a plasma torch. ${ }^{11)}$ Here, electrons and atoms realize thermal equilibrium having little difference in their temperatures. To pro-

Table 1. Chemical Compositions of Fly Ash (mass\%)

\begin{tabular}{ccccccccc}
\hline & $\mathrm{LOI}$ & $\mathrm{SiO}_{2}$ & $\mathrm{Al}_{2} \mathrm{O}_{3}$ & $\mathrm{Fe}_{2} \mathrm{O}_{3}$ & $\mathrm{CaO}$ & $\mathrm{MgO}$ & $\mathrm{SO}_{3}$ & $\mathrm{~K}_{2} \mathrm{O}$ \\
\hline $\mathrm{A}$ & 6.0 & 53.0 & 22.1 & 6.8 & 3.2 & 0.9 & 0.8 & 1.9 \\
\hline *LOI : Loss on ignition
\end{tabular}

Table 2. Physical Properties of Fly Ash

\begin{tabular}{lcc}
\hline \multicolumn{1}{c}{ Item } & Value & Unit \\
\hline Density & 2.3 & $\mathrm{~g} / \mathrm{cm}^{3}$ \\
Loss on ignition & 6 & $\%$ \\
Particle size & 16.6 & $\mu \mathrm{m}$ \\
Blaine surface area & 380 & $\mathrm{~m}^{2} / \mathrm{kg}$ \\
\hline
\end{tabular}

duce such state, high electric energies are required. The other one is cold plasma, which can be easily produced under a relatively low pressure using a low energy. ${ }^{12}$ Although the temperature of reaction gas are similar to that of atmosphere, the temperature of electrons is characterized as being in a state as high as 10 to 100 times of the latter temperature. Cold plasma can promote chemical reactions difficult to be realized by general methods through production of reactants with a very high chemical reactivity.

Plasma types can be divided into ICP (Inductively Coupled Plasma) type and CCP (Capacitively Coupled Plasma) type. ${ }^{13)}$ The ICP type is a method of generating plasma by application of an AC voltage, allowing high-density plasma to be obtained. The CCP type is a method of applying DC or $\mathrm{AC}$, which has an advantage that wide areas can be evenly reacted by formation of uniform plasma although it does not have a high density. Therefore, the CCP type was adopted in the present study where wide areas should be evenly treated by dispersion of powder samples in a container.

The drawing and the picture of the plasma equipment produced for the experiments are shown in Fig. 1. For fly ash, $10 \mathrm{~g}$ of sample was evenly dispersed in a thin layer to allow plasma to reach even the inside after fixing a guide to $1 \mathrm{~mm}$-thick silicon wafer. And the experiments for elimination of unburned carbon were conducted with the silicon wafer placed in the plasma equipment. For the vacuum gauge and controller device, Type146 of MKS Co. was used, and plasma reaction was implemented by maintaining the vacuum of 0.5 torr after treatment first at $10^{-3}$ torr. Since the fly ash is an electrical insulator, $\mathrm{RF}$ of $13.56 \mathrm{MHz}$ was used. The experiments were conducted with the temperature of the substrate for placement of a sample container inside the vacuum chamber being set at $150^{\circ} \mathrm{C}$. For the gas injected into the plasma apparatus, $\mathrm{O}_{2}$ was used. Experimental conditions employed for the cold plasma are shown in Table 3.

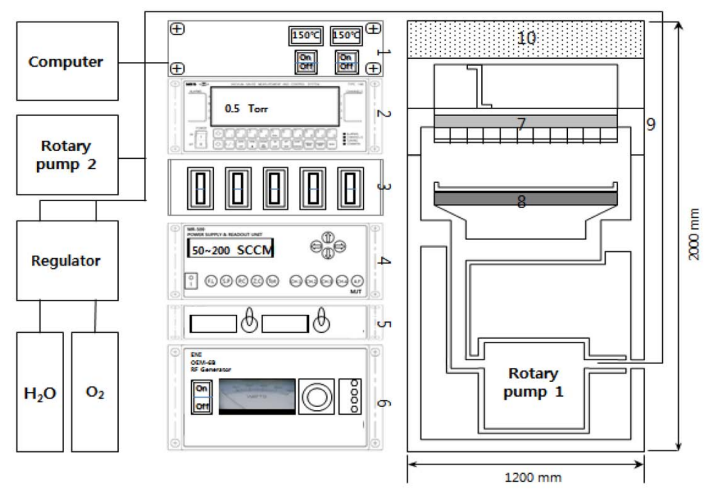

(a)

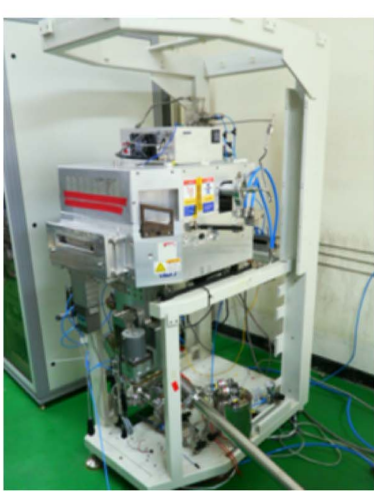

(b)

1: Substrate temp. controller, 2: Vacuum gauge controller , 3: Circuit breaker, 4: Power supply \& readout unit, 5: Auto matching controller, 6: RF controller, 7: Plasma shower head(30 cm), 8: Substrate , 9: Vacuum chamber, 10: Cooling fan

Fig. 1. Cold plasma equipment for experiment : (a) schematic diagram and (b) exterior appearance. 
Table 3. Experimental Conditions Studied in this Work for Elimination of Unburned Carbon in Fly Ash

\begin{tabular}{lcc}
\hline \multicolumn{1}{c}{ Item } & Value & Unit \\
\hline Working pressure & 0.5 & torr \\
Substrate heater & 150 & ${ }^{\circ} \mathrm{C}$ \\
Plasma power & 150 & $\mathrm{~W}$ \\
Gas flow & 80 & $\mathrm{sccm}$ \\
\hline
\end{tabular}

\section{2 heat treatment}

To identify changes in crystal phases as a function of heating temperature for fly ash according to the experimental results of Lee et al, the fly ash heated in the range of $500 \sim 1200^{\circ} \mathrm{C}$ for $3 \mathrm{~h}$ was examined. ${ }^{10)}$ According to the result, sintering phenomenon occurred among particles starting from $600^{\circ} \mathrm{C}$ although there was little change in the fly ash heated to $500^{\circ} \mathrm{C}$, and feldspar peaks began to appear for a change in mineral phases resulting from a chemical reaction at $1000^{\circ} \mathrm{C}$. Based on such result, tests for the present experiment were conducted in air. within a box furnace set at $500^{\circ} \mathrm{C}$.

\subsection{Measurement of physicochemical properties}

For the fly ash before and after removal of unburned carbon, the loss on ignition, BET specific surface area (Microtrac Co. Adsotrac DN-04) and the particle size distribution (Microtrack-9320 HRA) were measured. Also, the particle shapes and the localized elements were analyzed by using SEM (Hitachi Co. S-4800)-EDS (Horiba Co. EX-250). And the extents of reduction in unburned carbon were evaluated by using the loss on ignition, which was measured by ignition until a constant weight was reached at $950^{\circ} \mathrm{C}$ according to KS L 5405.

\section{Results and Discussion}

\subsection{Property changes resulting from plasma treatment}

\subsubsection{Loss on ignition}

Figure 2 shows a change in the loss on ignition as a function of treatment time by two methods. For the change form in the loss on ignition, the two treatment methods exhibited a similar tendency except for the fact that the treatment took a long time in the case of heat treatment. To obtain samples with the loss on ignition less than 1.0\%, 6 times of treatment for $10 \mathrm{~min}$ each was required for the cold plasma method, and the loss on ignition by the heat treatment was $0.9 \%$ when heat treated at $500^{\circ} \mathrm{C}$ for $5 \mathrm{~h}$.

\subsubsection{BET specific surface area}

The change in BET specific surface areas as a function of the loss on ignition for fly ash is shown in Fig. 3. In the case of cold plasma method, BET specific surface areas were reduced in proportion to the loss on ignition as indicated by $9,250 \mathrm{~m}^{2} / \mathrm{kg}$, for the loss on ignition of $6.0 \%, 4,250 \mathrm{~m}^{2} / \mathrm{kg}$ for the ignition of $3.0 \%$, and $1,690 \mathrm{~m}^{2} / \mathrm{kg}$ for the loss on ignition

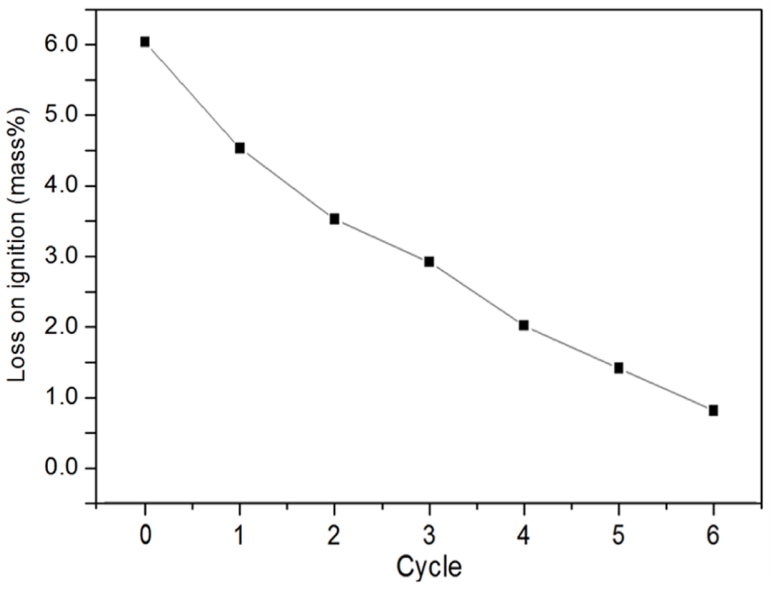

(a)

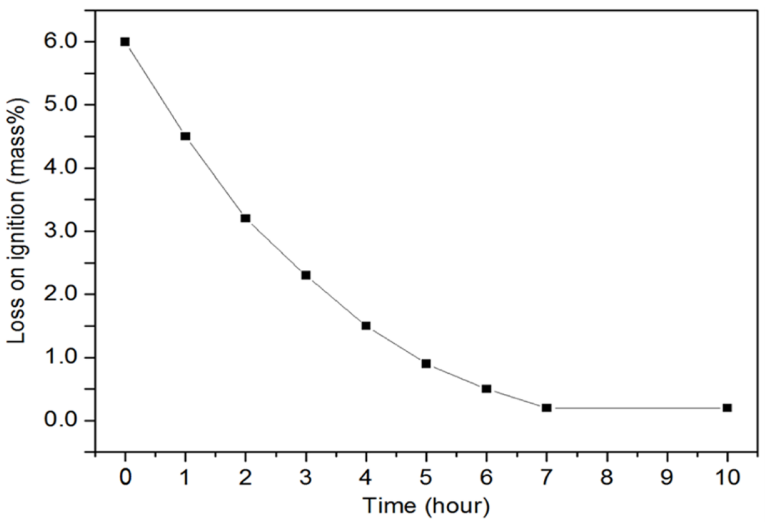

(b)

Fig. 2. Effects of treatment time on the loss on ignition of fly ash : (a) plasma treatment and (b) heat treatment.

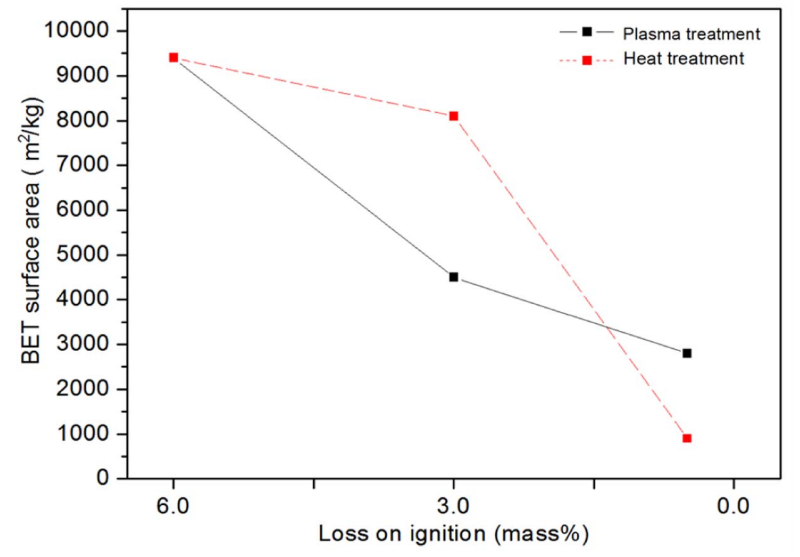

Fig. 3. The relationship between loss on ignition of fly ash and BET specific surface area of fly ash as a function of treatment methods.

of $1,690 \mathrm{~m}^{2} / \mathrm{kg}$, while the reduction width in BET specific surface areas was small at $1,100 \mathrm{~m}^{2} / \mathrm{kg}$ for the heat treatment. In the case of cold plasma, micro fine pores governing the specific surface areas among unburned carbon are considered to have been removed. In the case of cold plasma, 
since the temperature of electrons are characterized as being in the state as high as about 10 to 100 times of the temperature of reaction gas although the latter temperature is similar to the temperature of atmosphere, Radicals and electrons are considered to penetrate through interior of the unburned carbon particles to remove micro fine pores.

In the case of heat treatment, however, since treatment times are short and removal reaction occurs slowly from particle surfaces of unburned carbon, the change in BET specific surface areas down to the loss on ignition of $3 \%$ is small compared with the case of plasma method. However, in the case of heat treatment, the BET specific surface areas are drastically reduced after the loss on ignition of $3 \%$. As the reason for such observation, adhesion phenomenon between particles is considered to have occurred along with elimination of pores within the fly ash.

\subsubsection{Change in particle size distribution}

Particle size distribution curves for the fly ash with unburned carbon treatment are shown in Fig. 4. In the case of cold plasma treatment method, the phenomenon was displayed where large particles were reduced and small particles were slightly increased when the loss on ignition was lowered to less than $1.0 \%$. Such changes may be interpreted as the phenomenon occurring when the small particles confined within were freed as the carbon component was removed by plasma. On the other hand, in the case of heat treatment, although the phenomenon was observed where fine powder was reduced together with coarse powder at the loss on ignition of $0.3 \%$ in a similar fashion to that of cold plasma, the phenomenon of increase of coarse powder occurred at the loss on ignition of $0.5 \%$. This suggests that adhesion phenomenon of particles appeared because of continuous heating.

Particle size distribution characteristics for fly ash due to elimination of unburned carbon were evaluated by RosinRammler distribution function. Eq. (1) shows Rosin-Rammler particle size distribution.

$$
R\left(D_{p}\right)=10.0 \cdot e^{-b D_{p}^{n}}
$$

where, $R\left(D_{p}\right)=$ accumulated fraction $(\%), D_{p}=$ particle diame$\operatorname{ter}(\mu \mathrm{m}), \mathrm{b}=$ particle diameter coefficient, $\mathrm{n}=$ particle diameter index. The Eq. (1) may be revised as follows.

For the particle diameter De for which $R\left(D_{p}\right) \fallingdotseq$ $100 e^{-1}=36.8(\%)$, the Eq. $(2)$ is obtained since $\mathrm{b}=(1 / \mathrm{De})^{\mathrm{n}}$.

$$
R\left(D_{p}\right)=10 e^{-\left(D_{p} / D_{e}\right)^{n}}
$$

where the $\mathrm{n}$ value is an integer showing the range of particle size distribution and the range of particle size distribution becomes the wider, the smaller the $\mathrm{n}$ value. Particle characteristics values for Rosin-Rammler distribution function are shown in Table 4.

In the case of cold plasma, the particle size (De) was reduced from $30.6 \mu \mathrm{m}$ to $20.6 \mu \mathrm{m}$ as the loss on ignition for

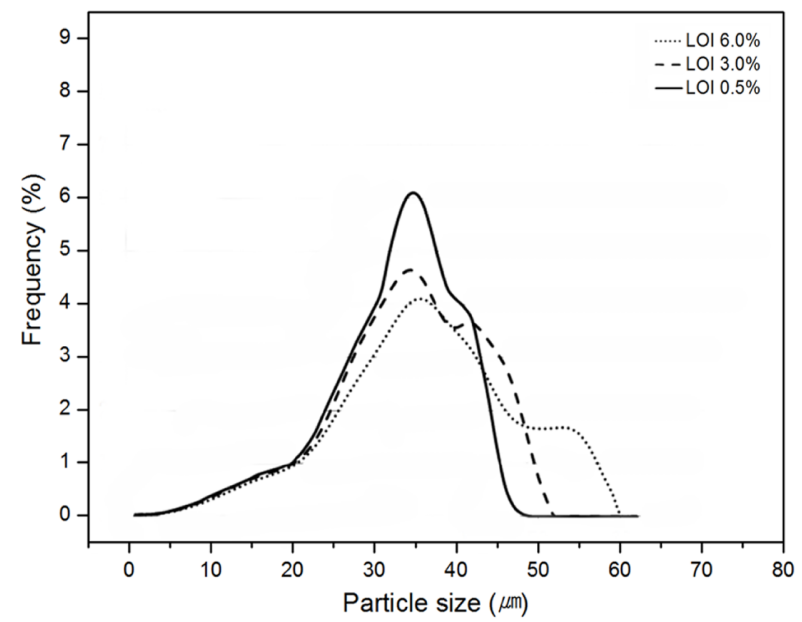

(a)

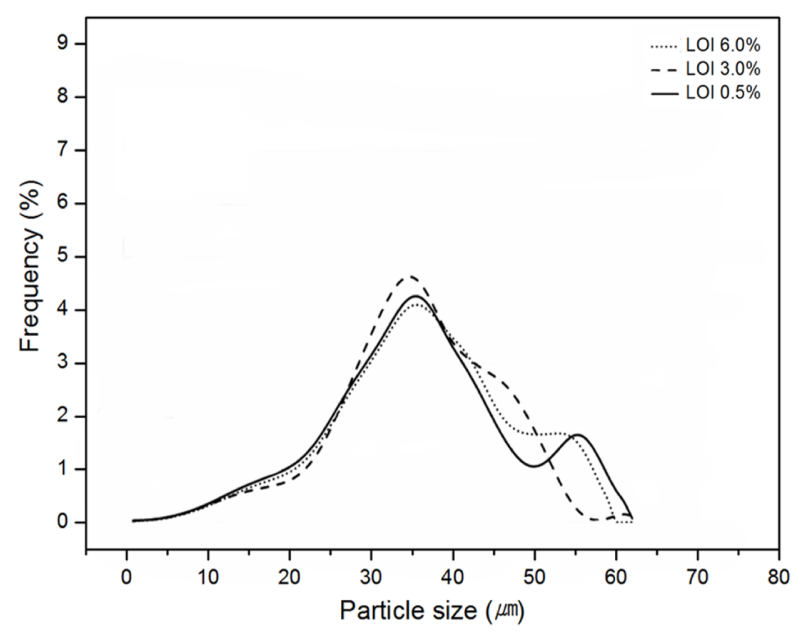

(b)

Fig. 4. Particle size distribution curves of fly ash as a function of loss on ignition (LOI) : (a) plasma treatment and (b) heat treatment.

Table 4. Rosin-Rammler Parameters of Fly Ashes as a Function of Treatment Methods

\begin{tabular}{cccc}
\hline Sample & \multicolumn{3}{c}{ Rosin-Rammler parameter } \\
\cline { 2 - 4 } *P: Cold plasma, & $\mathrm{n}$ & De $(\mu \mathrm{m})$ & $\mathrm{R}^{2}$ \\
H: Heat treatment & 0.82 & 30.6 & 0.99 \\
Raw fly ash $6.0 \%$ & 1.11 & 26.0 & 0.99 \\
P LOI $3.0 \%$ & 1.33 & 18.6 & 0.99 \\
P LOI 0.5\% & 0.93 & 25.6 & 0.99 \\
H LOI $3.0 \%$ & 0.78 & 29.7 & 0.99 \\
H LOI $0.5 \%$ & & & \\
\hline
\end{tabular}

fly ash was lowered. Also, the $\mathrm{n}$ value was increased from 0.82 to 1.23 , where such change means that the overall particle size distribution was narrowed down.

While the particle size (De) was reduced for the loss on ignition down to $3.0 \%$ in the heat treatment unlike in the cold plasma treatment, the particle size showed a tendency for increase at the loss on ignition of $0.5 \%$. The $n$ value was 


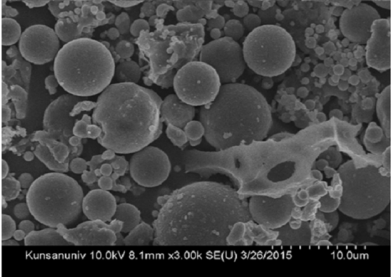

(a)

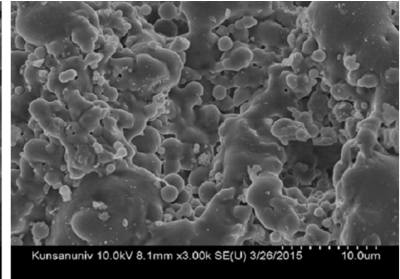

(b)
Fig. 5. SEM photographs of fly ashes at loss on ignition $0.5 \%$ : (a) plasma treatment and (b) heat treatment.

slightly increased to 0.93 at the loss on ignition of $3.0 \%$ and reduced to 0.78 at $0.5 \%$. Namely, although the particle size distribution was narrowed as the loss on ignition was reduced from $6.0 \%$ to $3.0 \%$, it was widened again as the loss on ignition was reduced from $3.0 \%$ to $0.5 \%$. To find the cause for such phenomenon, a SEM picture is presented which shows a change in particle forms for fly ash. In the case of cold plasma, particle forms for the fly ash according to changes in the loss on ignition of the fly ash.

Figure 5 shows a SEM picture for the treatments by cold plasma and heat treatment, where severe adhesion phenomenon among small particles is observed in the case of heat treatment, although particle agglomeration due to plasma is not visible. Therefore, in the case of heat treatment, coarse powder is increased due to occurrence of adhesion phenomenon with elimination of unburned carbon although the coarse powder is reduced initially due to elimination of the unburned carbon. Since the particle agglomeration phenomenon does not occur in the cold plasma, however, the particle size distribution curves showing reduction of coarse powder as a result of reduction of the loss on ignition are displayed.

\subsubsection{Change in forms of unburned carbon as a function of} loss on ignition

Changes in the unburned carbon particles among fly ash are shown in Fig. 6 as a function of loss on ignition due to the use of cold plasma and heat treatment. In Fig. 6, the content results for localized $\mathrm{C}$ element according to EDS are also indicated. As shown in Fig. 6 (a), the unburned carbon is porous, having the interior filled with spherical particles composed of $\mathrm{Al}$ and $\mathrm{Si}$ elements, etc. When the loss on ignition is lowered to $4.5 \%$ (b) by using cold plasma, large pores come to exist as fine pores in the unburned carbon are eliminated. When the loss on ignition is lowered to $3.0 \%(\mathrm{~d})$, the frameworks of carbon powder are removed, exposing spherical particles contained within. For the loss on ignition of $0.5 \%$ (f), no particles of unburned carbon powder could be found, and spherical particles which were confined within the unburned carbon are observed to have been freed. Also, heteromorphic particles of $15 \mu \mathrm{m}$ are the ash powder with unburned carbon removed, and the carbon element was not analyzed.

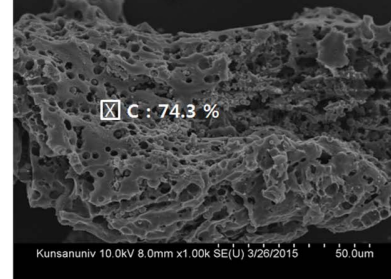

(a)

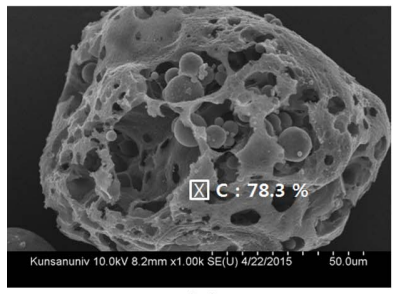

(b)

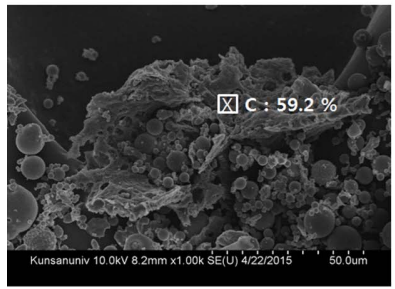

(d)

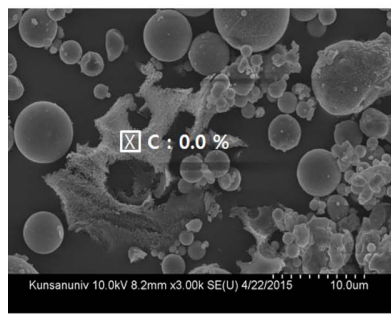

(f)

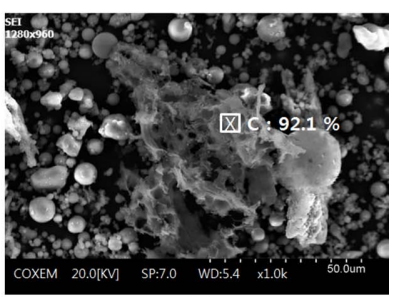

(c)

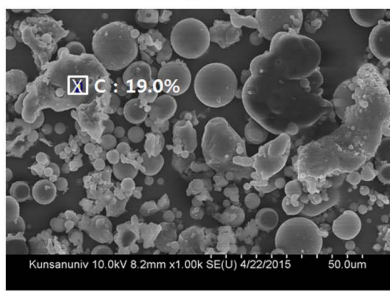

(e)

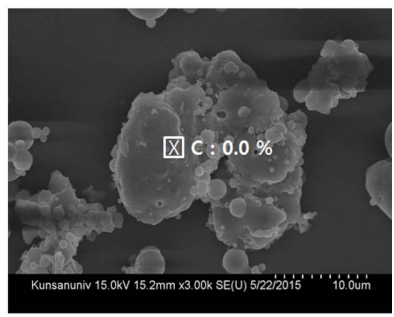

(g)
Fig. 6. SEM images of fly ash according to variation of loss on ignition (LOI) : (a) LOI 6.0\%, raw fly ash, (b) LOI $4.5 \%$, plasma treatment, (c) LOI $4.5 \%$, heat treatment, (d) LOI 3.0\%, plasma treatment, (e) LOI 3.0\% heat treatment, (f) LOI $0.5 \%$, plasma treatment, and (g) LOI $0.5 \%$, heat treatment.

On the other hand, although unburned carbon particles were cut when the loss on ignition was lowered to $4.5 \%$ (c) by heat treatment, fine pores were partly visible in a similar way to the untreated case. When the loss on ignition was lowered to $3.0 \%$ (e) by heat treatment at $500^{\circ} \mathrm{C}$ for more than $3 \mathrm{~h}$, the framework part of unburned carbon was disintegrated to expose particles inside without occurrence of adhesion phenomenon. When the loss on ignition was reduced to $0.5 \%$ (g) by ignition for more than $6 \mathrm{~h}$, the adhesion phenomenon of inside particles was observed although the unburned carbon powder was almost entirely eliminated. Schematic diagrams for elimination of unburned carbon by cold plasma and heat treatment derived on the basis of such phenomenon are shown in Fig. 7 and Fig. 8 . 


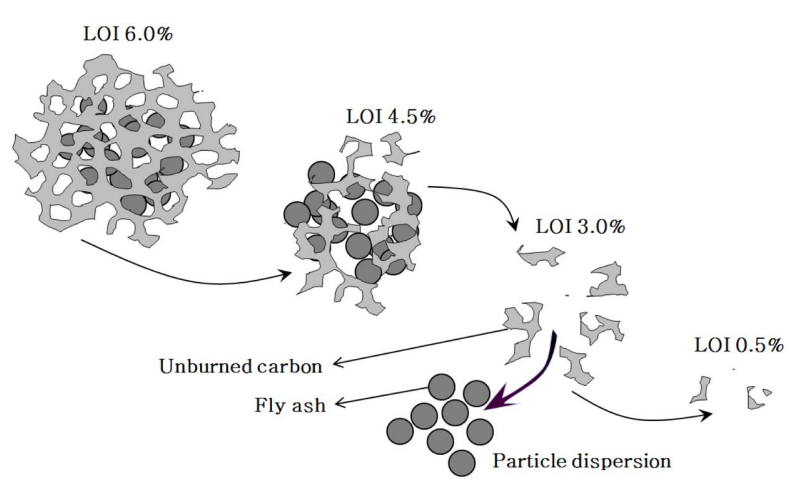

Fig. 7. Schematic diagram for elimination of unburned carbon in fly ash by plasma treatment.

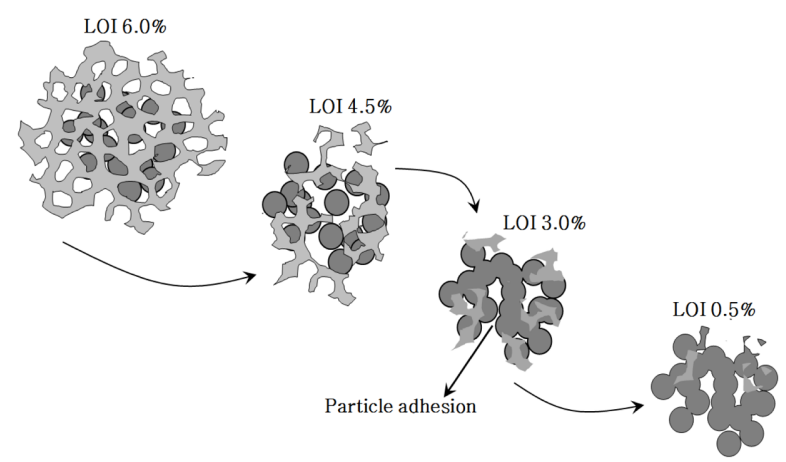

Fig. 8. Schematic diagram for elimination of unburned carbon in fly ash by heat treatment.

\section{Conclusions}

By selection of cold plasma method and heat treatment as technologies for reduction of unburned carbon to less than $1.0 \%$ for the fly ash containing high unburned powder, the powder characteristics were reviewed as a function of loss on ignition. Elimination of unburned carbon to less than $1.0 \%$ was possible by both cold plasma and $500^{\circ} \mathrm{C}$ heat treatment. When the unburned carbon was removed down to $3.0 \%$, the reduction of BET specific surface areas was more drastic for cold plasma than for heat treatment. On the other hand, in the case of heat treatment, the reduction ratio of specific surface areas down to the loss on ignition of $3.0 \%$ was smaller, since the carbon powder was removed from the particle surfaces of unburned carbon. Up to the loss on ignition of $3.0 \%$, the mean particle diameters were reduced, showing a tendency toward narrowing down of the particle size distribution, irrespective of treatment methods. In the case of loss on ignition of $0,5 \%$ with unburned carbon almost entirely eliminated, adhesion phenomenon between particles occurred in the heat treatment, resulting in drastic reduction of specific surface areas and increase of mean particle diameters In the cold plasma, on the other hand, no adhesion phenomenon occurred so that mean particle diameters were reduced for improvement in powder characteristics, although specific surface areas were reduced due to elimination of unburned carbon. In addition, fine powder was slightly increased as small spherical particles which were confined within unburned carbon particles were freed due to elimination of the framework parts of unburned carbon.

\section{Acknowledgments}

This article is a result of the study performed under the auspices of 2014 Operation Project of University-Institute Joint Research Center for Korea Research Council of Fundamental Science \& Technology.

\section{REFERENCES}

1. H. J. Feuerborn and T. Eck, "Coal Combustion Products in Europe - Production, Qualities and Use, Today and Tomorrow," Proceedings of the International Conference Euro Coal Ash 2010, Copenhagen, Denmark, 27-8 May, 2010

2. S. Nagataki, E. Saka, and T. Takeuchi, "The Fluidity of Fly Ash Cement Paste with Superplasticizer," Cem. Concr. Res., 14 631-38 (1984).

3. Y. Kocak and S. Nas, "The Effect of Using Fly Ash on the Strength and Hydration Characteristics of Blended Cements," Constr. Build. Mater., 73 25-32 (2014).

4. E. Sakai, S. Miyahara, S. Ohsawa, S. H. Lee, and M. Daimon, "Hydration of Fly Ash Cement," Cem. Concr. Res., 35 1135-40 (2005).

5. J. Payá, J. Monzó, E. Peris-Mora, M.V. Borrachero, R. Tercero, and C. Pinillos, "Early-Strength Development of Portland Cement Mortars Containing Air Classified Fly Ashes," Cem. Concr. Res., 25 449-56 (1995).

6. J. K. Kim, M. Y. Kim, H. D. Lee, and S. C. Kim, "Performance Test of Semi-Demo Scale Electroseparator for Removing Unburned Carbon from Fly Ash," J. Korea Soc. Waste Manag., 13 [1] 5-10 (2008).

7. W. Zhang and R. Honaker, "Studies on Carbon Flotation from Fly Ash," Fuel Process. Technol., 139 236-41 (2015).

8. J. M. Veranth, T. H. Fletcher, D. W. Pershing, and A. F. Sarofim, "Measurement of Soot and Char in Pulverized Coal Fly Ash," Fuel, 79 1067-75 (2000).

9. M. Jalal, A. Pouladkhan, O. F. Harandi, and D. Jafari, "Comparative Study on Effecrs of Class F Fly Ash, Nano Silica and Silica Fume on Properties of High Performance Self Compacting Concrete," Constr. Build. Mater., 94 90104 (2015).

10. S. H. Lee, A. Kawakami, E. Sakai, and M. Daimon, "The Fluidity of Cement Pastes with Fly Ashes Containing a Lot of Carbon," J. Korean Ceram. Soc., 40 [3] 219-24 (2003).

11. E. Bormashenko, G. Whyman, V. Multanen, E. Shulzinger, and G. Chaniel, "Physical Mechanism of Interaction of Cold Plasma with Polymer," J. Colloid Inter. Sci., 448 175-79 (2015).

12. L. Bai, H. Jin, C. Lu, F. Yuan, S. Huang, and J. Li, "RF Thermal Plasm a-Assisted Metallothermic Synthesis of Ultrafine $\mathrm{ZrB}_{2}$ Powders," Ceram. Int., 41 7312-17 (2015).

13. Y. Sakamoto, S. Maeno, N. Tsubouchi, T. Kasuya, and M. Wada, "Comparison of Plasma Parameters in CCP and ICP Processes Appropriate for Carbon Nanotube Growth," J. Plasma Fusion Res., 8 587-90 (2009). 